\title{
Reducing deforestation and forest degradation: leakage or synergy?
}

\author{
Arild Angelsen $^{1}$ and Philippe Delacote ${ }^{2}$
}

Agricultural expansion is the main deforestation driver, while forest degradation is due to non-sustainable poaching and harvesting of forest products. Policies to reduce emissions from deforestation and forest degradation (REDD) thus focus on limiting agricultural expansion and non-sustainable (and often illegal) harvesting. The feedbacks between these two policy instruments are rarely discussed. Does reduced deforestation indirectly decrease or enhance forest degradation? How does better control on non-sustainable harvesting influence deforestation? Using a simple agricultural household model, we assess the impact of a Payment for Environmental Services (PES) on both deforestation and harvesting, and the impact of increasing the control on illegal harvesting on deforestation. We show that when land and labor are substitutes, both policies have positive feedbacks and win-win potential. Conversely, when production factors are complements, they have negative feedbacks and need to be taken into account by the public policies. A novel result is that the production factors can become substitutes if distance costs are high, making a win-win situation more likely.

Keywords: deforestation, REDD, payment for environmental services, agricultural expansion, illegal harvesting, poaching, leakage, synergies

1. School of Economics and Business, Norwegian University of Life Sciences, Norway

2. INRA, UMR 356 Économie Forestière, F-54000 Nancy, France

Agroparistech, Engref, Laboratoire d'économie forestière, F-54000 Nancy, France

Climate Economics Chair, Paris, France

This paper has been presented at the EAERE annual conference (Rome, 2011), and to a research seminar at Copenhagen University. We acknowledge useful comments from participants. We also thank Jo Albers and Pablo AndresDomenech for their feedback. The research leading to these results has received funding from the European Union's Seventh Framework Programme (FP7/20072013) under grant agreement no 243950.

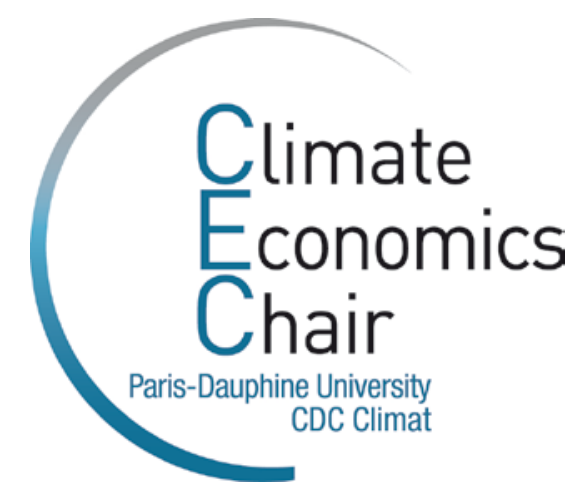





\title{
Reducing deforestation and forest degradation: leakage or synergy?
}

June 11, 2014

\begin{abstract}
Agricultural expansion is the main deforestation driver, while forest degradation is due to non-sustainable poaching and harvesting of forest products. Policies to reduce emissions from deforestation and forest degradation (REDD) thus focus on limiting agricultural expansion and non-sustainable (and often illegal) harvesting. The feedbacks between these two policy instruments are rarely discussed. Does reduced deforestation indirectly decrease or enhance forest degradation? How does better control on non-sustainable harvesting influence deforestation? Using a simple agricultural household model, we assess the impact of a Payment for Environmental Services (PES) on both deforestation and harvesting, and the impact of increasing the control on illegal harvesting on deforestation. We show that when land and labor are substitutes, both policies have positive feedbacks and win-win potential. Conversely, when production factors are complements, they have negative feedbacks and need to be taken into account by the public policies. A novel result is that the production factors can become substitutes if distance costs are high, making a win-win situation more likely.

Keywords: deforestation, REDD, payment for environmental services, agricultural expansion, illegal harvesting, poaching, leakage, synergies
\end{abstract}

${ }^{*}$ This paper has been presented at the EAERE annual conference (Rome, 2011), and to a research seminar at Copenhagen University. We acknowledge useful comments from participants. We also thank Jo Albers and Pablo Andres-Domenech for their feedback. The research leading to these results has received funding from the European Union's Seventh Framework Programme (FP7/2007-2013) under grant agreement no 243950. 


\section{Introduction}

Agricultural expansion is responsible of the highest share of deforestation in the developing world (IPCC (2007), Rudel (2007), Angelsen (2009); Hosonuma et al. (2012)). Effective policies aiming to reduce deforestation must therefore target agricultural expansion. However, when the agents of deforestation are poor agricultural households, they frequently mix their activities between agriculture and (sometimes illegal) forest products harvesting and poaching, which can lead to forest degradation (Godoy et al. (1997), Pattanayak and Sills (2001), Delacote (2007), Delacote (2009)). In situations of imperfect markets, as frequently found in remote, forested areas, different activities are interlinked in household decision making. In this context, what happens if the policy to reduce deforestation focuses on agricultural expansion only, while the deforestation agents are also illegal loggers and poachers? ${ }^{1}$ Similarly, how does better control of illegal harvesting influence deforestation? In other words, do policies aiming at reducing deforestation and illegal harvesting present policy makers with a menu of synergies or trade-offs (leakage) between the two interventions?

Leakage or "emission displacement" (in official climate language) refers to a situation where reduction in emissions in one area or activity leads to higher emissions of greenhouse gases (GHG) in another. There are several channels of leakage (Wunder (2008)), including activity shifting among agricultural households. Addressing leakage is a major challenge in designing and implementing effective climate mitigation policies.

In this paper we address one particular channel of leakage between policy interventions, namely those resulting from agricultural households shifting between various emission-generating activities. We develop a simple agricultural household model. Households allocate labor both to agriculture and forest harvesting (both timber and non-timber forest products), and choose the area to deforest for agricultural purposes. Policies to reduce agricultural expansion may take the form of payment for environmental services (PES), cf. Wunder (2005). We consider a PES scheme in which agricultural households are paid to reduce their agricultural expansion compared to a business as usual (BAU) scenario. While such a scheme should - at least in theory - reduce deforestation, its impact on illegal harvesting is not straightforward. Similarly, controlling illegal harvesting can be a policy instrument to contain forest degradation, and we ask how this will impact on deforestation.

\footnotetext{
${ }^{1}$ From now on, we will employ the term illegal harvesting, when talking of illegal logging and poaching of (both timber and non-timber) forest products. Note, however, that agricultural expansion may also be illegal, when forest clearing is made without the clearer having property rights or legal restrictions apply on forest conversion.
} 
Our results show that the relation between production factors is the main factor influencing those feedback effects. When labor and agricultural land are substitutes, the PES scheme yields a win-win outcome: it directly decreases deforestation and indirectly decreases labor allocated to illegal harvesting and thereby forest degradation. Similarly, better control over illegal harvesting leads to less labor being allocated to this activity, and deforestation also decreases. In this case, both policy instruments have positive feedbacks. In contrast, when both factors are complements, the PES scheme generates a shift in labor allocation from agriculture to illegal harvesting. In this case, both policy instruments imply a trade-off between avoided deforestation and forest degradation. Our simulations based on Brazilian data show that a situation with factor complementarity is more likely than a situation with factor substitutability.

A novel feature of the model is the introduction of distance costs. Whether the factors are substitutes or complements in the net benefit function does not only depend on the technical properties of the agricultural production function but also the level of the distance costs. A surprising result is that high distance costs may create a substitution effect between land and labor, even if the factors are technically complementary, making a win-win outcome more likely.

Section 2 presents the household model in the BAU case. Section 3 presents the policy instruments to reduce deforestation and forest degradation. Section 4 outlines direct and indirect outcomes of the forest policy in terms of avoided deforestation and illegal harvesting. Section 5 further elaborates on the role of distance costs on factor complementarity, and presents a simple numerical application of the model. Section 6 concludes and elaborates on the policy implications of our results

\section{A household model of agricultural expansion and forest harvest- ing}

In many regions of the developing world, poor rural communities expanding their agricultural land to improve their livelihood are major agents of deforestation. The households pursue a mix of economic activities (Banerjee and Duflo (2007)), including agriculture (both crops and cattle) and harvesting of wood (e.g. fuelwood and timber) and non-wood (e.g. fruits, edible plants and game meat) forest products. Those products may be directly consumed by the household or sold on local markets. One reason for high diversification is market incompleteness, where constrained access to (high transaction costs) output and labor markets makes rural households pursue a broad range of self-employing activities. Moreover, harvesting forest products is frequently considered 
an activity which is particularly attractive to households with few options in agriculture (small landholdings) and off-farm employment (Agarwal, 1991; Baland and Francois, 2005; Reddy and Chakravaty, 1999).

The labor market assumptions are critical for the logic and results of an agricultural household model (Amacher, 2009; Angelsen, 1999). If we assume that labor can be sold (and hired) freely at a given wage rate in a labor market (and more generally when markets are complete), the decisions of consumption and production are separable (Singh et al., 1986). The interaction between the two activities included in our model would disappear. A more realistic assumption is to incorporate labor market constraints into the model, for example, that farmers sell a fixed amount of labor in the market and allocate the remaining labor to productive activities and leisure in order to maximize utility. This is referred to as the Chayanovian approach. The consumptions and production decisions are taken simultaneously, and the model gives a subjective equilibrium wage rate (shadow wage) as the marginal rate of substitution between leisure and consumption, cf. Nakajima (1986).

Our model makes one more simplifying assumption, namely that leisure is also fixed. The problem is therefore to allocate a given amount of family labor $\bar{l}$ to agriculture $(l)$ and to illegal harvesting $(\bar{l}-l) .^{2}$ This keeps the model simple and tractable, and is sufficient to analyze our key problem, namely the interdependency between agricultural production and harvesting of forest products in a context where access to an off-farm labor market is constrained. The assumption is commonly used in in other studies (e.g. Amacher et al. (2009), Baland and Francois (2005), Delacote (2009)). A more complete Chayanovian model would enrich the analysis, but at a high costs in terms of model tractability and without changing the basic leakage mechanism analyzed in the paper. Further, the fixed off-farm labor assumption could be relaxed, for example, off-farm employment might be available but at higher transaction costs (lower effective wage).

The household also have to make the decision of how much land to use for agriculture $L$. The cost of land conversion and maintenance is $c L$ (net of any timber sale). The cost $c$ depends mainly on land tenure costs, property rights, land clearing costs. Households then make two decisions: (i) what size of land will be cultivated $L$, and (ii) how to allocate family labor between agriculture and illegal harvesting.

Forest clearing can be part of a long-term investment in agricultural land, which may require a dynamic model. In a general dynamic mode (Kerr et al., 2002), forest clearing takes place when (i) the net present value of forest clearing is positive, and (ii) the arbitrage condition holds, i.e. it

\footnotetext{
${ }^{2}$ The assumption is made here that harvesting is illegal. However, our analysis holds whenever harvest is considered non sustainable, whether it is legal or not. The case of legal forest harvesting is considered briefly in section 3.2 .
} 
must not be even more profitable to delay forest clearing (e.g. due to much lower clearing costs in the future). If we make the reasonable assumption that the arbitrage condition holds, that the (annual) agricultural rent increase relative to the forest rent over time, and that there is no strategic forest clearing (i.e. clearing forest to claim or strengthen property rights to the land), then Angelsen (1999) and Kerr et al. (2002) show that the dynamic problem boils down to a static problem of maximizing the current profit, and land is brought under cultivation once net agricultural rent outweighs the loss in forest rent. These assumptions will of course make the model more tractable, and we thus develop a timeless static model. Dynamic issues (such as price and technological change) can be addressed through comparative statics.

\subsection{Business-as-usual situation}

In the BAU case, no policy is implemented to control forest harvesting nor to reduce agricultural expansion. Assuming risk neutrality ${ }^{3}$, households choose their land and labor allocation to maximize net return from their activities:

$$
\max _{L, l} Y(l, L)=A(l, L)+H(l, L)-c L
$$

$A(l, L)$ is the net return from agriculture, $L$ the size of agricultural land (deforestation). We assume standard features of the agricultural production function: labor allocated to agriculture has positive and decreasing marginal productivity, representing congestion effects and tiredness; the most productive forest land is converted first to agriculture, resulting in positive and decreasing marginal productivity: $A_{l}=\frac{\partial A}{\partial l}>0$ and $A_{l l}=\frac{\partial^{2} A}{\partial l^{2}}<0 ; A_{L}=\frac{\partial A}{\partial L}>0$ and $A_{L L}=\frac{\partial^{2} A}{\partial L^{2}}<0$.

Forest harvesting provides net return of $H(l, L)$. Marginal labor productivity is positive and decreasing, i.e. negative in labor allocated to agriculture (l): $H_{l}=\frac{\partial H}{\partial l}<0$ and $H_{l l}=\frac{\partial^{2} H}{\partial l^{2}}<0$. Agricultural expansion affects illegal harvesting negatively, as it reduces the remaining forest stock: $H_{L}=\frac{\partial H}{\partial L}<0$ and $H_{L L}=\frac{\partial^{2} H}{\partial L^{2}}<0$.

Note that the cross-derivatives $A_{l L}$ of the agricultural production function and $H_{l L}$ of the illegal harvesting function are not explicitly signed (thus $Y_{l L}$ is not signed either). As we will show, the sign will influence the win-win potential of the REDD policies.

\footnotetext{
${ }^{3}$ Assuming risk aversion would bring potentially important modifications here. First, forest products harvesting is frequently mentioned as a risk-management tool against agricultural risk (Delacote (2007, 2009)). Second, if we assume, like we do in this paper, that forest product harvesting is illegal, risk-averse agents would consider here the risk of being caught and fined in their decisions. We can therefore assume here that risk neutrality tends to over-estimate illegal harvesting in the following model.
} 
F.o.c. give:

$$
\begin{aligned}
A_{l} & =H_{l} \\
A_{L}+H_{L} & =c
\end{aligned}
$$

which implicitly defines the optimal Business-As-Usual (BAU) labor allocation $l^{B A U}$, and agricultural expansion $L^{B A U}$. Note that (5) defines two types of costs of agricultural expansion: the clearing costs $c$ and the costs in terms of reduced forest stock and availability of forest products $\left(H_{L}\right) .{ }^{4}$

\subsection{How distance costs may influence factor complementarity}

As noticed earlier, we do not make any assumptions on factor complementarity or substitutability in the net income function ( $Y_{l L}$ may be positive or negative). In this section, we analyze how this relation between production factors may be related to distance costs. The literature on distance costs and forest products extraction (essentially non-timber forest products) is quite well-developed. Our approach follows Robinson et al. (2002) and Robinson et al. (2011): we distinguish between time spent on forest product harvesting (extraction intensity) and time spent on traveling (as determined by distance). Our contribution is that we consider that the time spent on traveling depends on the level of agricultural expansion or deforestation. Consider the case where agricultural expansion follows a circular von Thunen pattern, where agricultural land forms a circle around the village with forests beyond that agricultural frontier (Angelsen (1999)). Household members will then have to walk further to reach new agricultural fields and to harvest products in the forest. In addition, the cost of transportation of agricultural and forest products increases as fields and forests are further away from the village.

In the model and consistent with Robinson et al. (2002), we capture those costs related to distance and transportation by considering travel time as unproductive labor, i.e. it does not contribute to higher production of either agricultural or forest products.

We model labor allocated to illegal harvesting as follows: $f=\bar{l}-l-k L . k L$ represents the time spent on traveling (both walking to the field and carrying agricultural and forest products). $k$ is a parameter determined by terrain and local infrastructure. As $L$ increases, the share of unproductive labor dedicated to traveling increases as new agricultural land and available forests

\footnotetext{
${ }^{4}$ We implicitly assume here that the BAU scenario is of common knowledge. We thus avoid the issue about the definition and estimation of the BAU scenario, which is a major issue in the REDD debate (Busch et al. (2009), MeridianInstitute (2011)).
} 
are located further away from the homestead and the village. ${ }^{5}$ We can rewrite $H(l, L)=I(\bar{l}-l-k L)$. This specification implies a slight modification of model presented in equation 1 , in the sense that $L$ enters the illegal harvest return function trough labor allocation. We note that for sufficiently high distance costs, i.e. $k>\frac{\bar{l}-l}{L}$, illegal harvesting becomes totally unproductive and the household allocates all its effort to agriculture. For the remaining part of the paper, we will thus use function $H(l, L)$ for the general case, and function $I(\bar{l}-l-k L)$ for the distance costs case. Analogies between functions $H(l, L)$ and $I(\bar{l}-l-k L)$ are given in appendix 1, in order to facilitate switching between the two cases.

With this specification, we emphasize the impact of transport costs (via agricultural expansion) on forest harvesting. In reality, distance may also have an impact on agricultural productivity. While not directly included, it is implicitly considered in the concavity of the agricultural production function. Moreover, we can consider our results to be valid as long as distance costs have a greater impact on forest harvesting than agriculture, and forest harvesting productivity keeps being lower than agricultural productivity.

We can therefore specify expected net return in the following way:

$$
\max _{L, l} Y(l, L)=A(l, L)+I(\bar{l}-l-k L)-c L
$$

If the cross derivative of the net return function is negative (positive), then land and labor are substitutes (complements). A fair assumption to make is complementarity in agricultural production, i.e. $A_{l L}>0$ (as in the case of a Cobb-Douglas function with two inputs, for instance). In contrast, due to distance costs, land and agricultural labor generate substitution in the net return function through illegal harvesting : $I_{l L}<0$. Thus the question is how strong this complementarity is in agriculture, compared to the substitution in illegal harvesting implied by distance costs. Indeed, if distance costs are sufficiently large, land and labor may become substitutes in the net return function. It follows that land and labor are complement (substitute) in the net benefit function if $A_{l L}+k I_{f f}>0$. It also follows that the value of $k$, as well as the cross-derivatives will determine whether the factors are complements or substitutes. Land and labor are complementary if distance cost $(k)$ is sufficiently low:

$$
\begin{aligned}
Y_{l L} & =A_{l L}+\left(k I_{f f}\right)>0 \\
k & <\frac{A_{l L}}{-I_{f f}}
\end{aligned}
$$

\footnotetext{
${ }^{5}$ In many contexts, this type of transport cost is likely to be a function of total land cleared in the village rather than just the land cleared by the household. Nevertheless, as in a classic externality problem, the household only considers its own impact on transport costs in the first-order conditions. Our results are thus robust to this hypothesis.
} 
We summarize this result in Proposition 1:

Proposition 1 : For low distance costs $\left(k<\frac{A_{l L}}{-I_{f f}}\right)$, production factors are complement in the net return function. As distance costs increase $\left(k>\frac{A_{l L}}{-I_{f f}}\right)$, production factors become substitutes up to the point at which illegal harvesting is abandoned $\left(\bar{k}=k>\frac{\bar{l}-l}{L}\right)$.

An illustration on the influence of distance costs on factor complementarity is given in figure 1

To illustrate our simple model, we run simulations using more specified functions. ${ }^{6}$ The agricultural production function is calibrated based on the work by Marchand (2012), who estimated this function for the Brazilian Legal Amazon. The author estimated an aggregate agricultural production function as a translog function using not only land and labor, but also cattle and purchased inputs. As we in this paper only consider land and labor, we plug the average amount of cattle and purchased inputs into the calibrated function. We obtain the following form (values of the coefficients are given in appendix 2):

$$
A(l, L)=K .(l)^{\beta 1} \cdot\left(l^{2}\right)^{\beta 2} \cdot(\text { l.cattle })^{\beta 3} \cdot(\text { l.inputs })^{\beta 4} \cdot(L)^{\beta 5} \cdot\left(L^{2}\right)^{\beta 6} \cdot(\text { L.cattle })^{\beta 7} \cdot(\text { L.inputs })^{\beta 8} \cdot(\text { L.l })^{\beta 9} \text {. }
$$

Concerning the illegal harvesting return function, we adopt a simpler functional form:

$$
I(l)=z \cdot(\bar{l}-l-k L)^{\sigma}
$$

Several studies (Wunder, 2001; Angelsen and Wunder, 2003; Delacote, 2009) observe that extraction of forest products provides low returns to labor. In our calibration, we thus set the marginal labor productivity in illegal harvesting lower than in agriculture.

The first simulation (figure 1) shows that the cross-derivative of the net return function decreases with and is very sensitive to distance costs. More specifically, when we consider lower productivity on illegal harvest, the threshold $\bar{k}$ arrives quickly, and figure 2 shows that corner solutions, i.e. labor becoming unproductive in illegal harvesting due to distance costs, may arise quickly as distance costs increase. This result suggests that the two more likely situations are when factors are complement in the net return function, and when factor substitutability leads to corner solutions in which households focus on agriculture and abandon illegal harvesting.

\footnotetext{
${ }^{6}$ Simulations are performed using R Development Core Team (2012).
} 
Figure 1: Production factors tend to be complement (substitute) when distance costs are low (high)

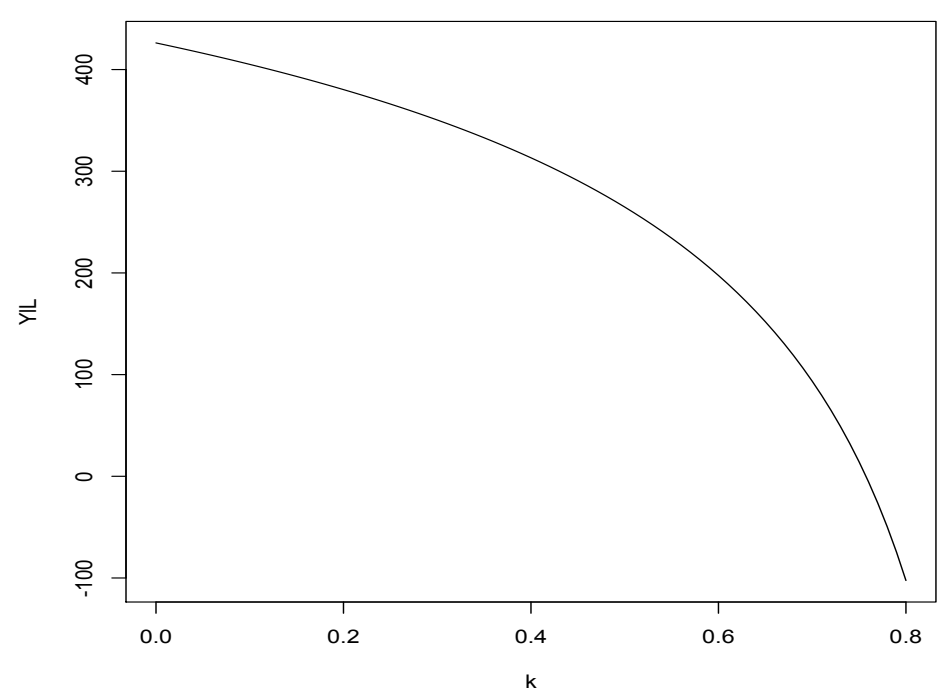

Parameters: appendix 2

Figure 2: Corner solutions arise when distance costs are sufficiently high

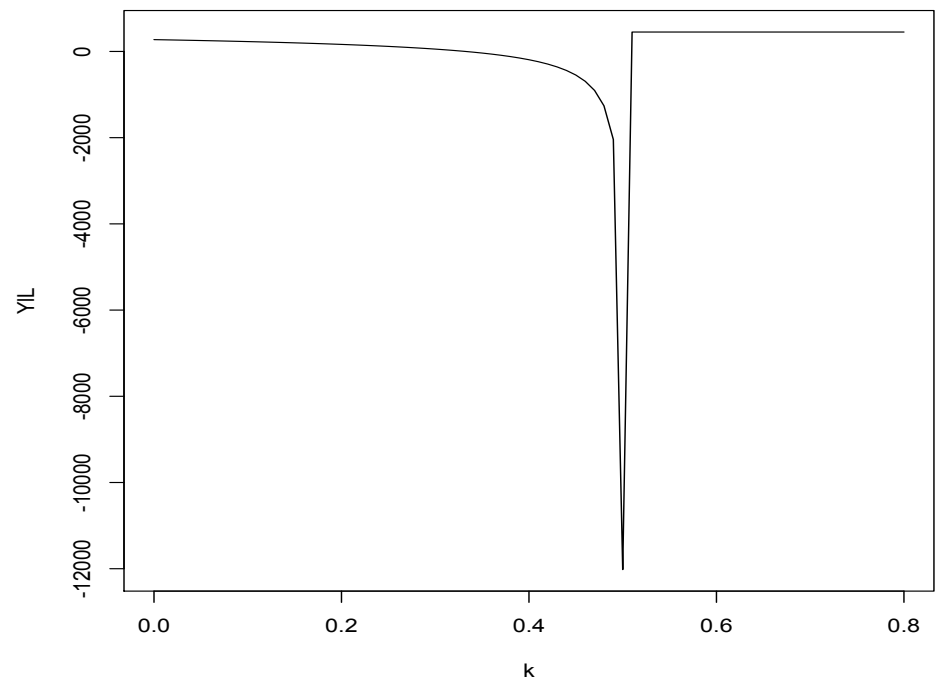

Parameters: appendix 2 


\section{REDD: addressing deforestation and forest degradation}

In our model we have one instrument to address deforestation and another one to address forest degradations. Many conservation programs being implemented are for the conservation of forests in general, such as the two biggest current PES programs in Costa Rica (see Arriagada et al. 2012) and Mexico (see Alix-Garcia et al. 2012). While recognizing that some policies aim to address both Ds simultaneously, we also find it useful analytically to consider two different policy instruments. The two Ds are normally driven by different activities. Deforestation is driven by the expansion of crop and cattle production, while degradation is driven by non-sustainable harvesting of forest products, such as collection of fuelwood (including for charcoal prodcution) and timber (e.g. Dokken et al. 2014). Supply chain policies, for example, will address specific products that are either linked to deforestation or forest degradation. Further, measuring and enforcing policies related to changes in forest area (deforestation) is also easier than measuring changes in the carbon per hectare (degradation).

\subsection{A PES scheme to avoid deforestation}

To reduce deforestation, the government offers a Payment for Environmental Services (PES) to the households, so that they are compensated for reducing their agricultural expansion. We assume that the PES contract only focuses on agricultural expansion and does not consider illegal harvesting. Indeed, PES schemes are only likely to function or be implemented where property rights are in place and respected, and to focus on legal activities and not on the informal sector.

We consider the following PES scheme. The regulator (government) has full information about the BAU level of deforestation $L^{B A U}$. Estimating the accurate level of BAU level of deforestation is a critical issue, but that discussion is not the purpose of this paper (Angelsen (2008a)). The household announces how much land it will convert $L^{P E S}$. The payment to compensate avoided deforestation is then simply proportional to the difference between the two variables: $r\left(L^{B A U}-L^{P E S}\right) . \quad r$ is the amount paid to the household per unit of land which is not deforested. ${ }^{7}$ We assume perfect monitoring: the policy maker can check with certainty the actual deforestation rate, and agents do not cheat on the PES contract. An interesting extension would be to consider imperfect information

\footnotetext{
${ }^{7}$ Note here that the PES may become a tax if $L^{P E S}>L^{B A U}$, which is somehow contrary to the voluntary nature of PES schemes. However, this case should not happen in our model, since agents are necessarily better off decreasing their deforestation rates. At the extreme, they could choose $L^{P E S}=L^{B A U}$, and would get the same return as under BAU.
} 
about the BAU baseline, or in the monitoring of actual deforestation. Clearly, getting information on the BAU deforestation for individual households is a non-trivial task.

We do not discuss explicitly the price setting in the PES scheme, $r$, which is considered as given and constant. In reality, $r$ could be calibrated based on different considerations. First, households may be paid individually according to their opportunity costs. In this case, the policy maker, in order to minimize the cost of the policy, just ensures that households are just marginally better off with the policy than without it. Second, a fixed price may be offered to all households, so that they reduce deforestation. In this case, households self select themselves: they accept the PES if and only if it makes them better off. Finally, the PES can be set in order to compensate for the value of the environmental service, e.g the carbon sequestered in non-deforested forests. Leplay et al. (2011) compare those different PES models for price setting, while Delacote et al. (2013) shows how the objective of the PES project manager influence the price setting.

\subsection{Addressing illegal harvesting: improved control quality}

We make the implicit assumption that labor allocated to forest harvesting increase forest degradation and carbon emissions, i.e. that the harvest rates are beyond the sustainable levels. To reduce forest harvesting, the government implements measures to control it. For example, households may be randomly inspected, and have to pay a fine if they are convicted of illegal harvesting. It follows that the household keeps the return from illegal harvesting only if it is not controlled and convicted. $\alpha$ is the exogenous conviction probability times the fine, which is proportional to the amount of illegal harvesting. The parameter then describes the control quality and can be seen as an indicator of institutional efficiency: a larger $\alpha$ corresponds to more effective institutions, while,for example, corrupted civil agents may be related to a low $\alpha$. The policy maker may thus choose to invest resources in order to increase control efficiency $\alpha$. Expected return from illegal harvesting is thus: $(1-\alpha) H(l, L)$.

This policy can also be given a broader interpretation. Not all non-sustainable harvesting of forest products may be illegal. The policy can then be interpreted as a tax on forest products, internalizing the externality of excessive forest harvesting. More generally, it can be related to any policy that lowers the price of forest products, e.g. promotion of more efficient cooking stoves that reduce the demand (and price) of charcoal. 


\subsection{The household factor allocation with the REDD policy}

The household's maximization problem with the two REDD policies in place becomes:

$$
\max _{L, l} Y(l, L)=A(l, L)+(1-\alpha) H(l, L)-c L+r\left(L^{B A U}-L\right)
$$

$l^{P E S}$ and $L^{P E S}$ are implicitly defined by the f.o.c:

$$
\begin{aligned}
A_{l} & =(1-\alpha) I_{l}, \\
A_{L}+(1-\alpha) H_{L} & =c+r
\end{aligned}
$$

Labor allocation is made so that marginal productivity of labor in agriculture equals expected marginal productivity of labor in illegal harvesting, factoring in the risk of being caught and fined. Land allocation is made to equalize the marginal productivity of agricultural land and marginal cost of land clearing plus the PES.

\section{Direct and indirect impacts of the REDD policy}

The policy maker has two policy choice variables: it can increase the payment in the PES scheme, by adjusting $r$; or it can increase the quality of control on illegal harvesting, by adjusting $\alpha$. The first variable plays on the household's land-use choice (equation 10), while the second variable plays on labor allocated to illegal harvesting (equation 9). However, both policy choice variables $(r, \alpha)$ have an indirect impact on the other household's choice variable $\left(l^{P E S}, L^{P E S}\right.$, respectively).

\subsection{Direct impacts of the policy on deforestation and illegal harvesting}

Comparing equation (3) and (10), we easily see that deforestation is smaller when the PES scheme is implemented than in the BAU case. We can infer more precisely the influence of the level of the payment $r$ on deforestation by using the implicit function theorem:

$$
\frac{\partial L^{P E S}}{\partial r}=\frac{1}{A_{L L}+(1-\alpha) H_{L L}}<0
$$

The direct effect of the PES is straightforward: increasing the amount offered to household increases the opportunity cost of deforesting for the agents. The decrease in deforestation is larger when the net return function is more concave in $L$, i.e. if the marginal productivity of land decreases rapidly. This should be the case in places where land is of heterogenous quality. In contrast, deforestation would be less sensitive to the PES when land is of homogenous quality. As 
an extreme case, deforestation may completely cease if the PES is set in order to completely cover the net return to agricultural production.

Second, it is also readily seen that increasing the quality of control on illegal harvesting will decrease labor allocated to the illegal activity:

$$
\frac{\partial l^{P E S}}{\partial \alpha}=\frac{H_{l}}{A_{l l}+(1-\alpha) H_{l l}}>0
$$

Here again, the effect is clear-cut: if controlling illegal harvesting becomes more efficient, expected return for the illegal activity decreases, which again decreases the incentive to allocate labor to that activity. Labor allocation to agriculture $l^{P E S}$ thus increases. We summarize these results as:

Proposition 2 : Increasing the payment for avoided deforestation will decrease deforestation, while increasing the control quality decreases labor allocated to illegal harvesting and thereby forest degradation.

Note that we consider prices to be exogenous (and implicit in the agricultural and forest harvesting functions). In general, endogenous prices would dampen the effects of the policies in our model in the area under the policy regime. For example, implementing PES would limit the agricultural land area, reduce supply of agricultural crops or beef, boost local prices of these products, and thereby limit the effectiveness of the policy. In addition, endogenous prices would add another channel of leakage: higher output prices could give incentive to increase production though deforestation (or illegal harvest) in other regions. An early study of such leakages, using a computable general equilibrium (CGE) model, is Cattaneo (2001).

Our simulations focusing on distance costs give an illustration of proposition 2. Figures 3 and 4 show the direct influence of the PES on deforestation in the case in which factors are complement and substitute, respectively. Similarly, figures 5 and 6 illustrate the direct impact of improving control quality on illegal harvesting. Figure 6 also suggests that increasing the control quality rapidly brings corner solutions in the substitution case. Indeed, it is easy to see that $\alpha$ has a multiplicative effect on distance costs, and thus make corner solutions happen faster. 
Figure 3: Increasing the PES decreases deforestation when production factors are complement

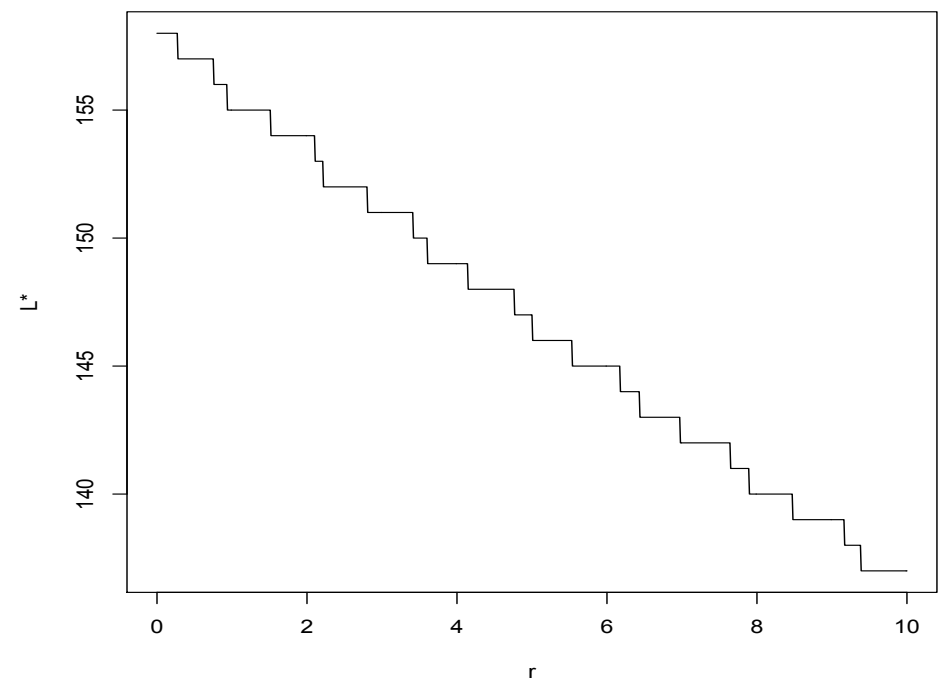

Parameters: appendix 2

Figure 4: Increasing the PES decreases deforestation when production factors are substitute

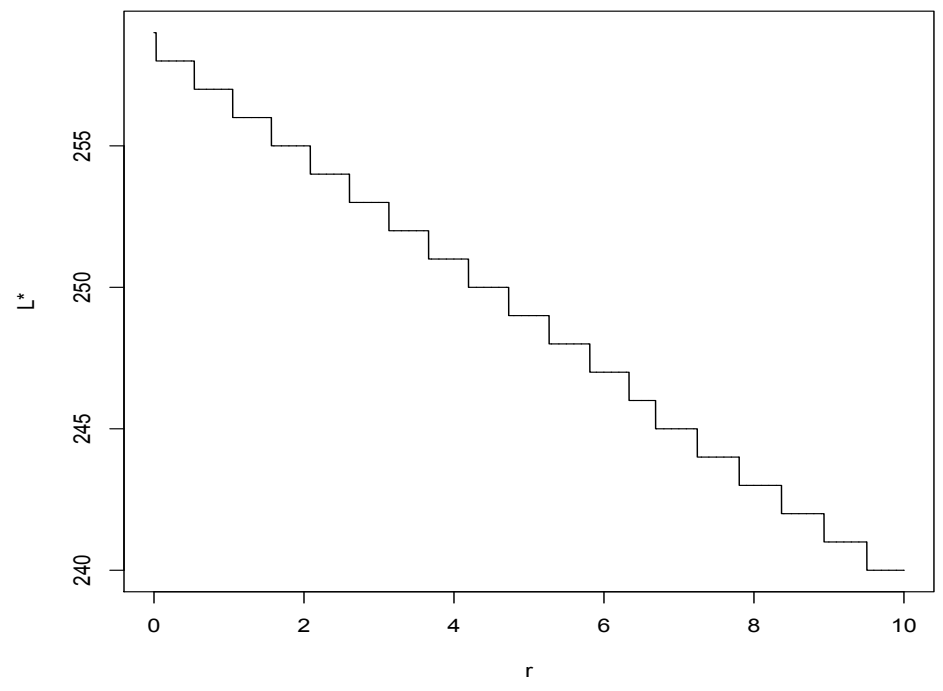

Parameters: appendix 2 
Figure 5: Increasing the control quality decreases illegal harvesting when production factors are complement

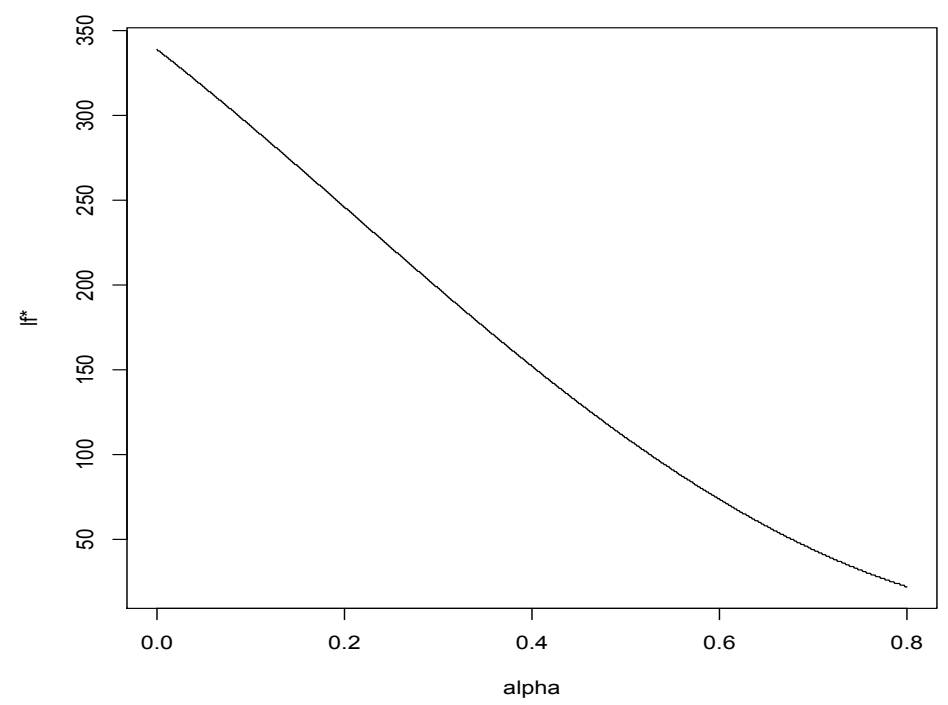

Parameters: appendix 2

Figure 6: Increasing the control quality decreases illegal harvesting when production factors are substitute

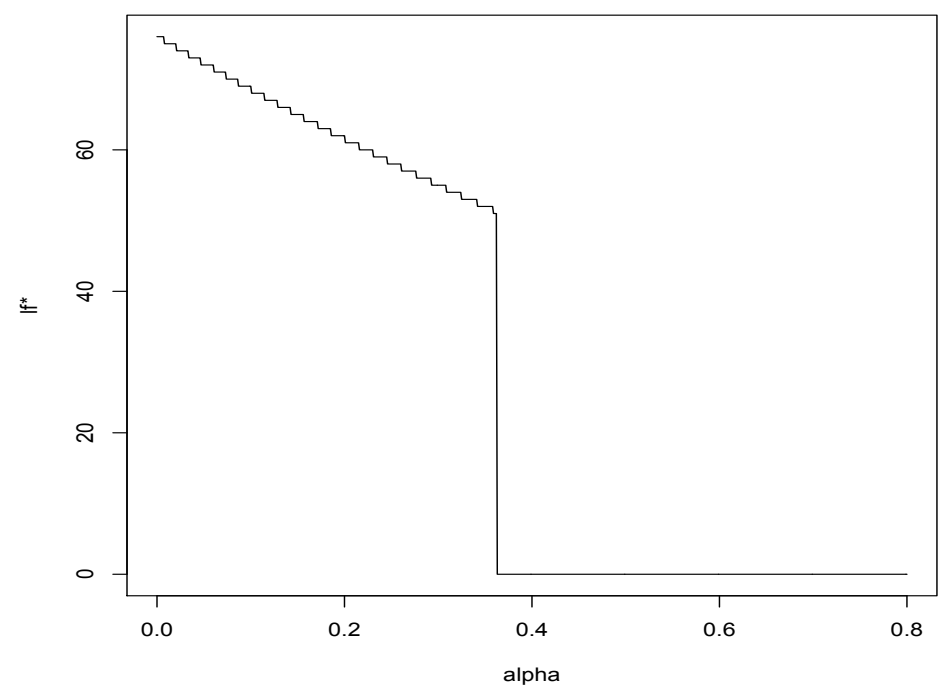

Parameters: appendix 2 


\subsection{Indirect impacts of the policy on deforestation and illegal harvesting}

Both policy instruments have also an indirect effect, which needs to be factored in. PES has an influence on the land use choice, which has an influence on labor allocation. Similarly, the control efficiency has an influence on labor allocation, which has an influence on land use.

Considering the impact of the PES scheme on illegal harvesting is equivalent to considering the impact of the PES scheme on labor allocation. By reducing agricultural expansion, the PES scheme may lead either to intensified agricultural production, or to free some labor which is allocated to illegal harvesting, or a combination of the two. In the first case, more labor is required in agriculture, and less labor is available to illegal harvesting. In the second case, the PES scheme leads to a shift in labor allocation, from agriculture to illegal harvesting.

The indirect impact of the PES on labor allocation can be expressed as follows:

$$
\frac{\partial l^{P E S}}{\partial r}=\frac{\partial l^{P E S}}{\partial L^{P E S}} \frac{\partial L^{P E S}}{\partial r}=-\frac{A_{l L}+(1-\alpha) H_{l L}}{A_{l l}+(1-\alpha) H_{l l}} \frac{1}{A_{L L}+(1-\alpha) H_{L L}}
$$

The second question is how a change in the quality of control on illegal harvesting will affect the level deforestation under the PES scheme. Using the implicit function theorem, we see that:

$$
\frac{\partial L^{P E S}}{\partial \alpha}=\frac{\partial L^{P E S}}{\partial l^{P E S}} \frac{\partial l^{P E S}}{\partial \alpha}=-\frac{A_{L l}+(1-\alpha) H_{L l}}{A_{L L}+(1-\alpha) H_{L L}} \frac{H_{l}}{A_{l l}+(1-\alpha) H_{l l}}
$$

We see from equation (13) and (14) that the indirect effect of the PES depends on the cross derivative of the net returns of agriculture and illegal harvesting.

\section{Proposition 3 :}

- Increasing the Payment for Environmental Services indirectly increases (reduces) illegal harvesting if land and labor are complement (substitutes) in the net return function: $A_{l L}+(1-$ $\alpha) H_{l L}>0\left(A_{l L}+(1-\alpha) H_{l L}<0\right)$.

- Improving the control quality on illegal harvesting indirectly increases (decreases) deforestation if land and labor are complements (substitutes) in the net return function: $A_{l L}+(1-\alpha) H_{l L}>0$ $\left(A_{l L}+(1-\alpha) H_{l L}<0\right)$.

Proof: $\quad \frac{\partial L^{P E S}}{\partial \alpha} \leq 0$ and $\frac{\partial l^{P E S}}{\partial r} \geq 0 \Longleftrightarrow Y_{l L} \leq 0 \Longleftrightarrow A_{l L}+(1-\alpha) H_{l L} \leq 0 \Longleftrightarrow$ $A_{l L}+(1-\alpha)\left(k I_{f f}\right) \leq 0 \Longleftrightarrow k \geq \frac{A_{l L}}{-I_{f f}}$

When the fields are far away from the main markets, or when slope and elevation are high, distance costs tend to be higher. Following proposition 1, it is then more likely that land and labor 
are substitute in the net function. In this case, increasing the PES decrease illegal harvesting, while increasing the control quality decreases deforestation.

A PES scheme will reduce the expansion of agricultural land. If land and labor are substitutes in the net return function, this reduction leads to agricultural labor being more productive. Thus, the households intensify agriculture (and thus reduce illegal harvesting) as a feedback of this reduced agricultural expansion. In contrast, if both factors are complement, the reduction in agricultural expansion reduces the marginal productivity of agricultural labor. The household thus decreases its use, leading to an increase of illegal harvesting.

Then strengthening the REDD policy (increasing the PES and the quality of illegal harvesting control) has win-win potential, i.e. has positive feedbacks, when land and labor are substitutes in agricultural production. In contrast, the feedback is negative of land and labor are complement in agricultural production. $^{8}$

Figures 7 and 8 show his indirect effects of the PES and the control quality when factors are complements. In this case, one instrument focusing on one particular objective produces leakage toward the other one.

The results are different in the case of substitutability. As discussed above, we then rapidly approach corner solutions (no illegal harvesting) when distance costs increase. With high distance costs, figure 9 shows that increasing the PES has at best a small effect on reducing illegal harvesting. Similarly, figure 10 shows that increasing $\alpha$ rapidly brings corner solution in which illegal harvesting is fully abandoned by the households. This implies an increase in deforestation

\section{Conclusion}

This paper has analyzed possible spillover effects (leakage) between the two D's in REDD policies: How do PES schemes aiming to reduce agricultural expansion (deforestation) influence non-sustainable harvesting of forest products (degradation)? How does better control of illegal harvesting impact deforestation? Our simple model demonstrates that the result depends on the nature of the relationship between land and labor. If land and agricultural labor are substitutes in the net return function, implementing PES presents policy makers with a win-win scenario: it directly slows down deforestation and indirectly decreases labor allocated to illegal harvesting.

\footnotetext{
${ }^{8}$ Forest products may have pretty inelastic demands in reality, as many of them are used for subsistence purpose. This inelastic demand may be related to an important concavity of the net return on illegal harvest, which can tend to reduce the extend (but not the nature) of result of equations (10) and (11).
} 
Figure 7: Increasing the PES increases illegal harvesting when production factors are complement

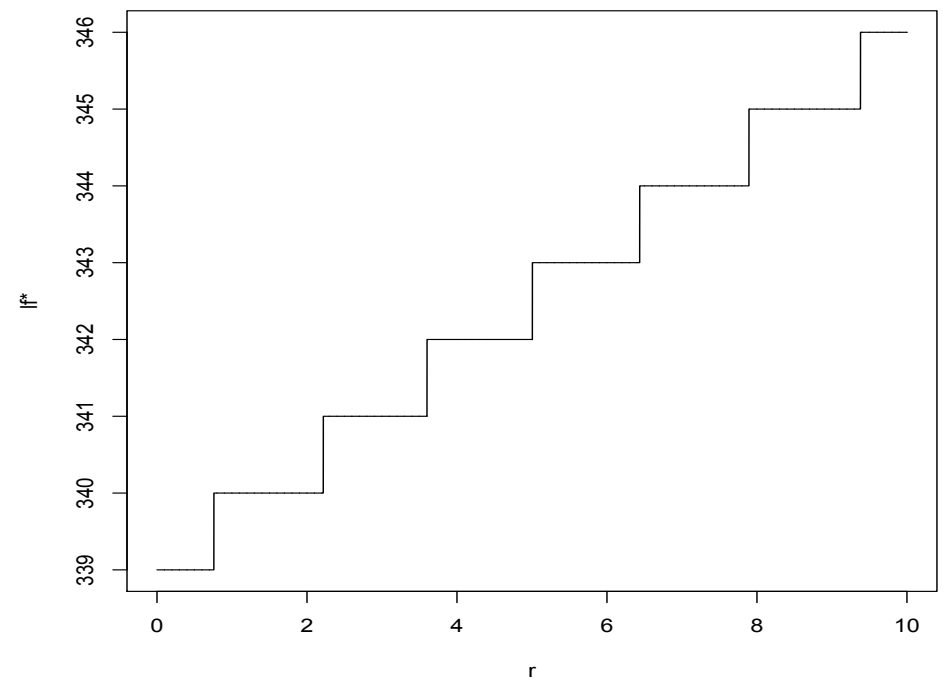

Parameters: appendix 2

Figure 8: Increasing the control quality increases deforestation when production factors are complement

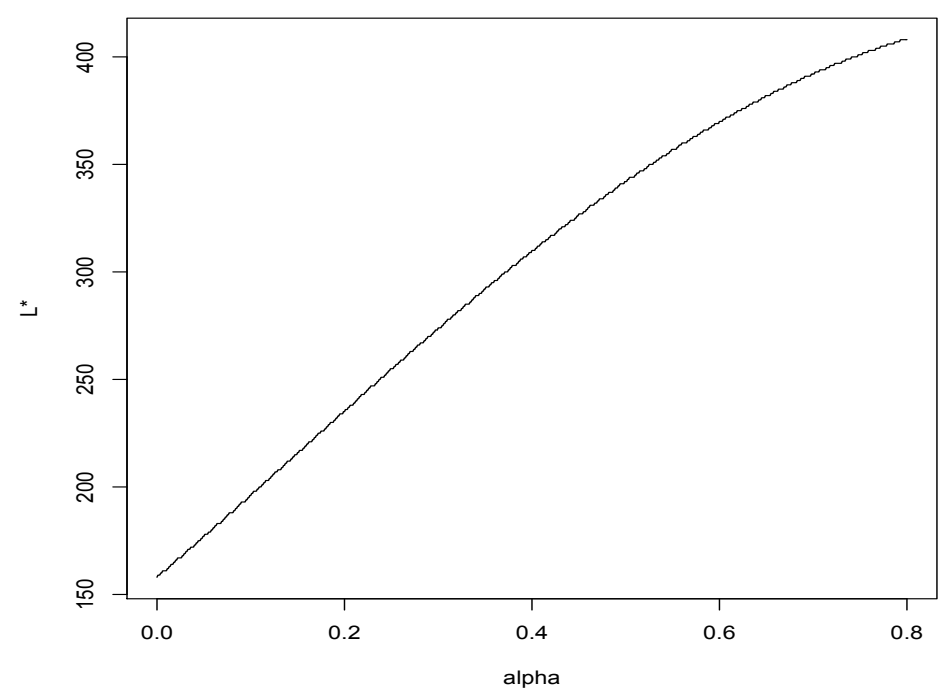

Parameters: appendix 2 
Figure 9: Increasing the PES decreases illegal harvesting when production factors are substitute

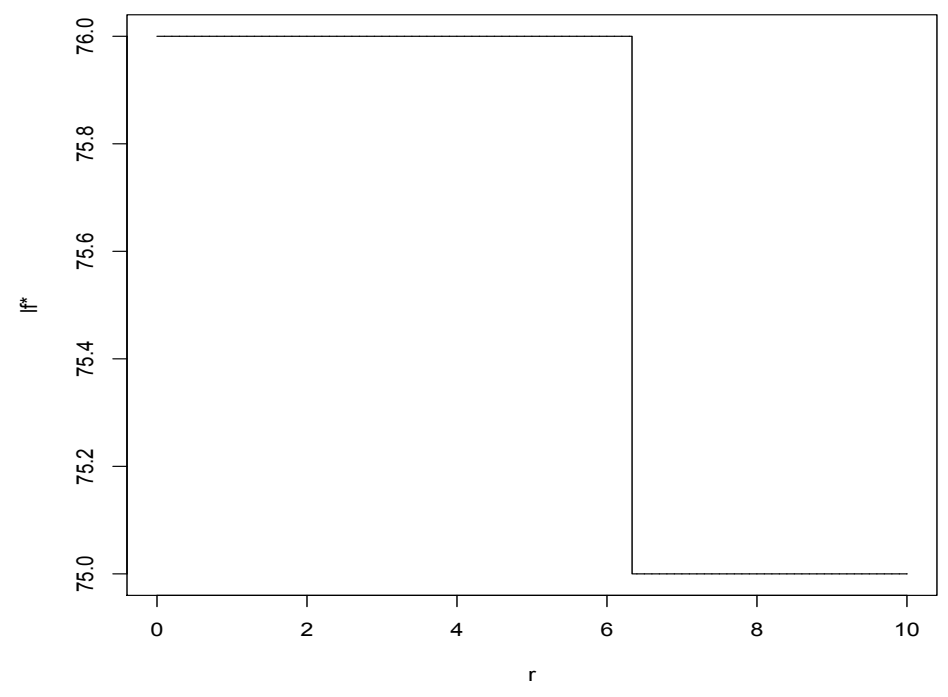

Parameters: appendix 2

Figure 10: Improving the control quality rapidly generates corner solutions when factors are substitutes

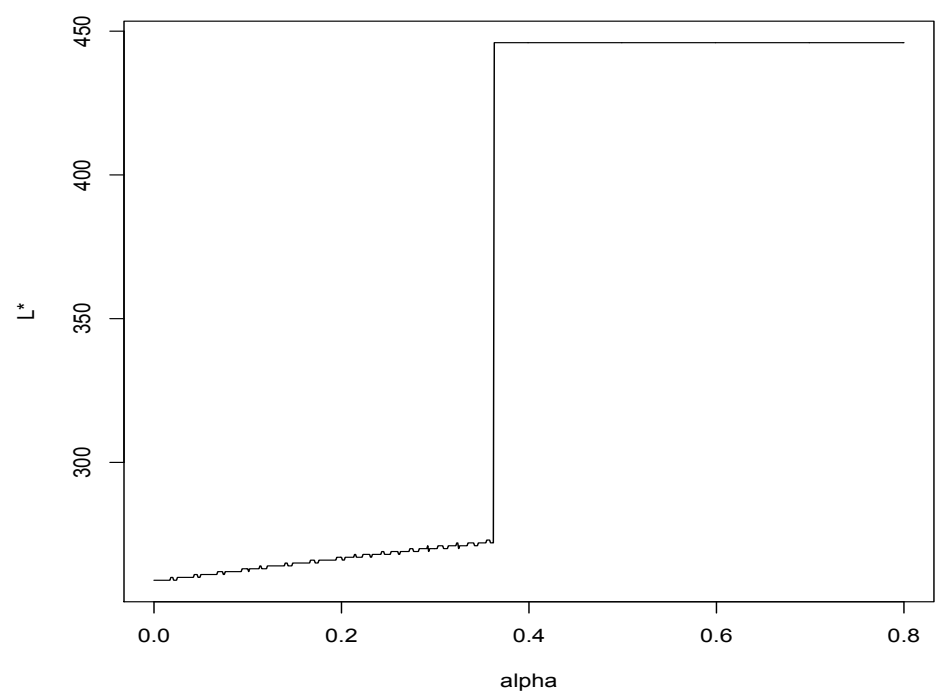

Parameters: appendix 2 
Similarly, improving the control quality directly reduces labor allocated to illegal harvesting and indirectly decreases deforestation. If land and labor are complements, which may be a more reasonable empirical assumption, increasing the payment for avoided deforestation indirectly increases illegal harvesting, while increasing the quality of control indirectly increases deforestation.

We also introduced distance costs in the model, and our results bring a clear prediction. Such costs may yield a win-win scenario even if we have technical complementarity between the factors in agricultural production. It then follows that win-win outcomes (both reduced deforestation and forest degradation) are more likely in regions with higher distance costs. Moreover, our simulations suggests that sufficiently high level of distance costs generates corner solutions in which labor allocated to illegal harvesting is no longer productive. In this case, leakage between deforestation and illegal harvesting is no longer a problem.

These results have several policy implications. First, they bring a very practical conclusion that a real policy mix of resource preservation is necessary in places where production factors are complement. PES scheme should be combined with strengthening of the control quality, to reduce efficiently indirect effects of the REDD policy. In particular, deforestation hotspots are likely to be in areas with high return to agricultural expansion, for example, caused by low distance costs, and these are exactly the areas where we are likely to face a win-lose outcome if only one policy is pursued.

Second, the PES scheme could be more effective if focused on places where distance costs are high (described by our parameter k) in order to get win-win outcomes. Empirically, high distance costs may be associated with low opportunity costs of deforestation (e.g. through high remoteness and lack of access to markets). In those cases of low opportunity costs, the implementation of the PES scheme presents policy makers with a more pleasant win-win scenario, in addition to the potential for larger emission reductions due to the smaller compensation payment needed .

Third, our simulations suggest it is less likely to have synergies when increasing the control quality on illegal harvesting, due to probable corner situations in which leakage between illegal harvesting and deforestation is important. This does not suggest that increased control should not be undertaken, but serves as a warning that win-win outcomes cannot readily be assumed.

Finally, our results are based on the assumption that households have constrained access to offfarm labor markets, which makes decisions on labor allocation to different activities inseparable. Better access to labor markets and development of attractive off-farm opportunities disconnects the two activities and make the two decisions separable. Improved labor market access can help to reduce those leakage situations. This result fits well with what other deforestation models have 
underscored, namely that providing better off-farm income generating opportunities can have a major forest conservation effect.

\section{Appendix 1: general case and distance cost case}

\begin{tabular}{|r|r|r|}
\hline General Case & Distance cost case & Sign \\
\hline \hline$H(l, L)$ & $I(\bar{l}-l-k L)$ & \\
\hline$H_{l}$ & $-I_{f}$ & $<0$ \\
\hline$H_{L}$ & $-k I_{f}$ & $<0$ \\
\hline$H_{l l}$ & $I_{f f}$ & $<0$ \\
\hline$H_{L L}$ & $k^{2} I_{f f}$ & $<0$ \\
\hline$H_{l L}$ & $k I_{f f}$ & $<0$ \\
\hline
\end{tabular}


Appendix 2: Value of the parameters of the simulation

\begin{tabular}{|c|c|c|}
\hline Variable & & \\
\hline K & & 10499.25 \\
\hline$\beta 1$ & & 0.709 \\
\hline$\beta 2$ & & 0.087 \\
\hline$\beta 3$ & & -0.1 \\
\hline$\beta 4$ & & -0.098 \\
\hline$\beta 5$ & & 0.18 \\
\hline$\beta 6$ & & -0.019 \\
\hline$\beta 7$ & & -0.021 \\
\hline$\beta 8$ & & -0.013 \\
\hline$\beta 9$ & & 0.047 \\
\hline cattle & & 2750 \\
\hline inputs & & 62436 \\
\hline & Figure 2 & Figure 1 \\
\hline $\mathrm{k}$ & & $\in[0,0.8]$ \\
\hline $\mathrm{c}$ & 100 & 100 \\
\hline $\bar{l}$ & 500 & 500 \\
\hline $\mathrm{z}$ & 10604.25 & 17848.73 \\
\hline$\sigma$ & 0.4 & 0.5 \\
\hline & Substitutability & Complementarity \\
\hline Figures & $4,6,9,10$ & $3,5,7,8$ \\
\hline $\mathrm{k}$ & 0.1 & 0.01 \\
\hline c & 100 & 100 \\
\hline $\bar{l}$ & 500 & 500 \\
\hline z & 10604.25 & 17848.73 \\
\hline$\sigma$ & 0.4 & 0.5 \\
\hline
\end{tabular}




\begin{tabular}{|r|r|r||r|r|}
\hline & \multicolumn{2}{|c|}{ Substitutability } & \multicolumn{2}{|r|}{ Complementarity } \\
\hline \hline Policy & PES & Control quality & PES & Control quality \\
\hline Parameters & $r \in[0,10]$ & $r=0$ & $r \in[0,10]$ & $r=0$ \\
& $\alpha=0$ & $\alpha \in[0,0.8]$ & $\alpha=0$ & $\alpha \in[0,0.8]$ \\
\hline \hline Deforestation & $\in[259,240]$ & $\in[259,446]$ & $\in[158,137]$ & $\in[158,408]$ \\
\hline Labor in illegal harvesting & $\in[76,75]$ & $\in[76,0]$ & $\in[339,346]$ & $\in[339,22]$ \\
\hline
\end{tabular}

\section{References}

Agarwal, B. (1991). Social security and the family: coping with seasonnality and calamity in rural India, pages 171-244. Social Security in Developing Countries, Ahmad, E.J. and Dreze, J. and Hills, J. and Sen, A. (eds.), Clarendon Press, Oxford. 2

Alix-Garcia, J. M., Shapiro, E. N., and Sims, K. R. E. (2012). Forest conservation and slippage: Evidence from mexico's national payments for ecosystem services program. Land Economics, 88(4):613-638.

Amacher, G., Koskela, E., and Ollikainen, M. (2009). Deforestation and land use under insecure property rights. Environment and Development Economics, 14(03):281-303. 2

Angelsen, A. (1999). Agricultural expansion and deforestation: Modelling the impact of population, market forces and property rights. Journal of Development Economics, 58(1):185-218. 2.2

Angelsen, A. (2008a). How do we set the reference levels for REDD payments? In Angelsen, A., editor, Moving ahead with REDD: Issues, options and implications. Centre for International Forestry Research (CIFOR). 3.1

Angelsen, A., editor (2008b). MOving Ahead With REDD: Issues, options and implications. CIFOR.

Angelsen, A. (2009). Realising REDD: National Strategies and Policy Options. Center for International Forestry Research (CIFOR). 1

Angelsen, A. and Wunder, S. (2002). Exploring the forest-poverty link. CIFOR Occasional Paper n40.

Angelsen, A. and Wunder, S. (2003). Exploring the forest-poverty link. Technical report. CIFOR Occasional Paper n40. 2.2 
Arriagada, R. A., Ferraro, P. J., Sills, E. O., Pattanayak, S. K., and Cordero-Sancho, S. (2012). Do payments for environmental services affect forest cover? a farm-level evaluation from costa rica. Land Economics, 88(2):382-399.

Baland, J. and Francois, P. (2005). Commons as insurance and the welfare impact of privatization. Journal of Public Economics, 89(2-3):211-231. 2

Banerjee, A. V. and Duflo, E. (2007). The economic lives of the poor. Journal of Economic Perspectives, 21(1):141-168. 2

Busch, J., Strassburg, B., Cattaneo, A., Lubowski, R., Bruner, A., Rice, R., Creed, A., Ashton, R., and Boltz, F. (2009). Comparing climate and cost impacts of reference levels for reducing emissions from deforestation. Environmental Research Letters, 4(4):044006. 4

Cattaneo, A. (2001). Deforestation in the brazilian amazon: Comparing the impacts of macro economic shocks, land tenure, and technological change. Land Economics, 77(02):219-240.

Delacote, P. (2007). Agricultural expansion, forest products as safety nets and deforestation. Environment and Development Economics, 12(02):235-249. 1, 3

Delacote, P. (2009). Commons as insurance: safety nets or poverty traps? Environment and Development Economics, 14(03):305-322. 1, 2, 3, 2.2

Delacote, P., Palmer, C., Baakegaard, R., and Thorsen, B. (2013). Unveiling information on opportunity costs in redd: who obtains the surplus when policy objectives differ? Resource and Energy Economics, forthcoming. 3.1

Dokken, T., Caplow, S., Angelsen, A., and Sunderlin, W. (2014). Tenure issues in redd+ pilot project sites in tanzania. Forests, 05(02):234-255.

Godoy, R.and O’Neill, K., Groff, S., Kostishack, P., Cubas, A., Demmer, J., McSweeney, K., Overman, J., Wilkie, D., Brokaw, N., and Martinez, M. (1997). Household determinants of deforestation by amerindians in honduras. World Development, 25(6):977-987. 1

Hosonuma, N., Herold, M., Sy, V. D., Fries, R. S. D., Brockhaus, M., Verchot, L., Angelsen, A., and Romijn, E. (2012). An assessment of deforestation and forest degradation drivers in developing countries. Environmental Research Letters, 7(4):044009. 1

IPCC (2007). Fourth Assessment Report: Climate Change 200\%: The AR4 Synthesis Report. Geneva: IPCC. 1 
Kerr, S., Talikoff, A., and Sanchez, A. (2002). The dynamics of deforestation: Evidence from costa rica. Technical report. Columbia University, Department of Economics Discussion Papers 0001-01.

Leplay, S., Busch, J., Delacote, P., and Thoyer, S. (2011). Implementation of national and international redd mechanism under alternative payments for environemtal services: theory and illustration from sumatra. Working papers, LAMETA, Universtiy of Montpellier. 3.1

Marchand, S. (2012). The relationship between technical efficiency in agriculture and deforestation in the brazilian amazon. Ecological Economics, 77(0):166 - 175. 2.2

MeridianInstitute (2011). Guidelines for REDD+ Reference Levels: Principles and Recommendations. Government of Norway. 4

Nakajima, C. (1986). \{CHAPTER\} 3 - subjective equilibrium of the farm household in basic models. In NAKAJIMA, C., editor, Subjective Equilibrium Theory of the Farm Household, volume 3 of Developments in Agricultural Economics, pages 21 - 35. Elsevier. 2

Pattanayak, S. and Sills, E. (2001). Do tropical forests provide natural insurance? the microeconommics of non-timber forest product collection in the brazilian amazon. Land Economics, 77(4):595-612. 1

R Development Core Team (2012). R: A Language and Environment for Statistical Computing. R Foundation for Statistical Computing, Vienna, Austria. ISBN 3-900051-07-0. 6

Reddy, S. and Chakravaty, S. (1999). Forest dependence and income distribution in a subsistence economy. World Development, 27(7):1141-1149. 2

Robinson, E. J. Z., Albers, H. J., and Williams, J. C. (2011). Sizing reserves within a landscape: The roles of villagers? reactions and the ecological-socioeconomic setting. Land Economics, 87(2):233-249. 2.2

Robinson, E. J. Z., Williams, J. C., and Albers, H. J. (2002). The influence of markets and policy on spatial patterns of non-timber forest product extraction. Land Economics, 78(2):260-271. 2.2

Rudel, T. (2007). Changing agents of deforestation: From state-initiated to enterprise driven processes, 1970-2000. Land Use Policy, 24. 1

Singh, I., Squire, L., and Strauss, J., editors (1986). Agricultural Household Models. Johns Hopkins University Press, Baltimore. 
Wunder, S. (2001). Poverty alleviation and tropical forests: What scope for synergies? World Development, 29(11):1817-1833. 2.2

Wunder, S. (2005). Payments for environmental services: some nuts and bolts. Center for International Forestry Research, Bogor. 1

Wunder, S. (2008). Moving ahead with REDD: Issues, options and implications, chapter How do we deal with leakage?, page 65 . CIFOR. 1 



\section{Working Paper Series}

$n^{\circ} 2013-11$

$n^{\circ} 2013-11$

$n^{\circ} 2013-10$
Reducing deforestation and forest degradation: leakage or synergy?

By Arild Angelsen and Philippe Delacote

Greenhouse gas mitigation in Chinese agriculture: distinguishing technical and economic potentials

By Wen Wang, Frank Koslowski, Dominic Moran, Dali Rani Nayak, Eli

Saetnan, Erda Lin, Liping Guo, Guodong Han and Xiaotang Jug

$n^{\circ} 2013-09$

Carbon and energy prices under uncertainty: A theoretical analysis of fuel switching with non-equally efficient power plants

By Vincent Bertrand

$n^{\circ} 2013-08$

A stochastic generalized Nash-Cournot model for the northwestern European natural gas markets: The S-GaMMES model

By Ibrahim Abada and Pierre-André Jouvet

$n^{\circ} 2013-07$

Governance of $\mathrm{CO}_{2}$ markets: Lessons from the EU ETS

By Christian de Perthuis and Raphael Trotignon

$n^{\circ} 2013-06$

Switching to biomass co-firing in European coal power plants: Estimating the biomass and $\mathrm{CO}_{2}$ breakeven prices

By Vincent Bertrand

$n^{\circ} 2013-05$

EU ETS Phase 3 benchmarks: Implications and potential flaws By Stephen Lecourt

Modeling of Emission Allowance Markets: A Literature Review

By Vincent Bertrand

Contact us :

Chaire Economie du Climat - Palais Brongniart (4e étage)

28 Place de la Bourse, 75002 Paris

Tel : +33 (0)173019331

Email : contact@chaireeconomieduclimat.org

Climate Economics

Chair

Paris-Dauphine University CDC Climat 